Original Paper

\title{
Two-Dimensional HPLC-MS/MS Determination of Multiple D-Amino Acid Residues in the Proteins Stored Under Various pH Conditions
}

\author{
Chiharu ISHII ${ }^{1}$, Tetsuya MIYAMOTO ${ }^{2}$, Shoto ISHIGO ${ }^{1,3}$, Yurika MIYOSHI ${ }^{1,3}$, Masashi MITA², \\ Hiroshi HOMMA ${ }^{2}$, Tadashi UEDA ${ }^{1}$, Kenji HAMASE*1 \\ ${ }^{1}$ Graduate School of Pharmaceutical Sciences, Kyushu University, 3-1-1 Maidashi, Higashi-ku, Fukuoka 812-8582, Japan \\ ${ }^{2}$ Department of Pharmaceutical Life Sciences, Kitasato University, 5-9-1 Shirokane, Minato-ku, Tokyo 108-8641, Japan \\ ${ }^{3}$ Shiseido Co., Ltd., 1-6-2 Higashi-shimbashi, Minato-ku, Tokyo 105-8310, Japan
}

\begin{abstract}
The formation of D-amino acid residues in proteins is considered as one of the deterioration processes, and the determination of these D-amino acid residues is highly expected for the screening of new biomarkers under various disease conditions. In the present study, a two-dimensional (2D) HPLC-MS/MS system following the hydrolysis with deuterium chloride $\left({ }^{2} \mathrm{HCl} /{ }^{2} \mathrm{H}_{2} \mathrm{O}\right)$ and derivatization of amino acids with 4-fluoro-7-nitro-2,1,3-benzoxadiazole (NBD-F) has been designed/developed and applied to the analysis of proteins stored under various conditions. As the target, 5 major D-amino acid residues (Ala, Asp, Glu, Pro and Ser) were selected. The analytical procedure was validated using a model peptide, $\mathrm{NH}_{2}$-Gly-Pro-Glu-Ala-Asp-Ser-Gly-OH, and the obtained calibration lines of $\% \mathrm{D}$ for the 5 target amino acids were linear with correlation coefficients greater than 0.998 . The RSD values for the intra-day precision and inter-day precision were lower than 5\%. In most of the proteins tested, the amounts of the D-Ser and D-Asp residues increased during storage, and the highest value (14\%, D-Ser) was observed in ovalbumin (OVA) after storage at $\mathrm{pH} 9.5$ for 4 weeks.
\end{abstract}

Keywords: Isomerization; Enantiomer separation; D-Amino acid residue; 2D-HPLC MS/MS

\section{Introduction}

Amino acids are the essential components for living beings, and all of the proteinogenic amino acids, except glycine (Gly), have a chiral carbon at the $\alpha$-position. It was long considered that no D-amino acid is present in higher animals at least as physiologically-active molecules, although all L-amino acids are predominantly observed [1]. However, due to the recent progress on the highly sensitive and stereoselective analytical techniques, several free D-amino acids have been discovered in the tissues and physiological fluids of mammals including humans $[2,3]$. For example, D-serine (D-Ser) is located in the frontal brain regions to be a neuromodulator via the $\mathrm{N}$-methyl-D-aspartate subtype of glutamate receptors $[4,5]$. D-Aspartate (D-Asp) exists in the endocrine and neuroendocrine tissues to regulate the synthesis and

"Corresponding author: Kenji HAMASE

Tel: +81-92-642-6598; Fax: +81-92-642-6598

E-mail: hamase@phar.kyushu-u.ac.jp secretion of hormones such as melatonin and testosterone [6-8]. It has also been reported that the amounts of several free D-amino acids are changed in patients with various diseases $[9,10]$. In the case of patients with renal disorders, D-alanine (D-Ala) and D-Ser levels in their plasma are correlated with the kidney function [11-13]. In the spinal cord of mice with amyotrophic lateral sclerosis, the amount of D-Ser increases along with progression of the disease [14].

Besides the free D-amino acids, the presence of D-amino acid residues has also been reported in several proteins [15]. D-Asp residues were observed in crystallin from the lens [16] and elastin from the aorta [17]. These D-Asp residues are considered to be involved in the progression of age-dependent diseases such as cataracts and arteriosclerosis. D-Ser residues were found in the

Received: 8 May 2017

Accepted: 27 May 2017

J-STAGE Advance Published: 4 June 2017

DOI: 10.15583/jpchrom.2017.009 
$\beta$-amyloid in the brain of patients with Alzheimer's disease [18]. Although the presence of several D-amino acid residues has been clarified, most of the reports focused on D-Asp and D-Ser. Since several D-amino acids, not only D-Asp and D-Ser, have been found in the free forms and their amounts changed under various disease conditions in mammals [19-24], these free D-amino acids are expected to be the new biomarkers. These lines of investigations strongly suggest that other D-amino acid residues might also exist in proteins, and they also are expected to be novel biomarkers in mammals. Therefore, an analytical method, which can simultaneously determine various D-amino acid residues, is highly desired.

To analyze D-amino acid residues in the peptides and proteins, several analytical techniques have already been reported. By the enantioselective Edman degradation, an amino acid residue existing at the $N$-terminal of the peptides/proteins can be sequentially determined one-by-one [25]. However, it is normally impossible to determine all of the amino acid residues in the whole protein. Analysis of the diastereomeric peptides following enzymatic digestion by proteases is useful for the trace analysis of D-amino acid residues, because the method does not need hydrolysis under extremely severe conditions $[26,27]$. However, it is restricted to the peptides such that the positions of the D-forms are already known and requires synthetic peptides to identify each diastereomeric peptide. Acid hydrolysis in combination with chiral amino acid analysis is widely used to enantioselectively determine all of the amino acid residues. However, most of the amino acid residues are frequently epimerized during hydrolysis. In fact, the amino acid residues in peptides were epimerized during the early stage of acid hydrolysis before being released as free amino acids [28]. This means that the hydrolysate includes both D-amino acids from the native D-amino acid residues of the proteins and those artificially produced during the acid hydrolysis. One of the effective strategies to solve these issues during hydrolysis is to hydrolyze the proteins using ${ }^{2} \mathrm{HCl} /{ }^{2} \mathrm{H}_{2} \mathrm{O}$ and distinguish the native $\mathrm{D}$-amino acid residues originally present in the proteins and the D-amino acids produced during the hydrolysis by the difference in their molecular weights $[29,30]$. By using ${ }^{2} \mathrm{HCl} /{ }^{2} \mathrm{H}_{2} \mathrm{O}$ for the acid hydrolysis, the $\alpha$-hydrogen of the amino acid was changed to deuterium in the D-amino acids racemized/produced during the acid hydrolysis, which can be discriminated by mass spectrometry due to the molecular weight change.

In our laboratory, a two-dimensional (2D) HPLC-MS/MS system was adopted following ${ }^{2} \mathrm{HCl} /{ }^{2} \mathrm{H}_{2} \mathrm{O}$ hydrolysis to analyze the trace levels of the D-amino acid residues in protein samples [31]. By using the method, various D-amino acid residues could be determined and wide applications to show the usefulness of the proposed procedure are required. In previous reports, relatively high amounts of the D-Ser residue were found in native OVA and that stored under mild alkaline conditions [31,32], and the chiral inversion of the amino acid residues in various proteins stored under different conditions is a matter of interest. Therefore, in the present study, the accumulation of 5 major D-amino acids, D-Ala, D-Asp, D-glutamate (D-Glu), D-proline (D-Pro) and D-Ser residues, in 4 vertebrate proteins (OVA, human serum albumin (HSA), hen egg lysozyme (HEL), human lysozyme (HL)) has been investigated. These proteins were stored under 3 $\mathrm{pH}$ conditions $(\mathrm{pH} 4.0,7.4,9.5)$ at $37^{\circ} \mathrm{C}$ up to 4 weeks, and non-negligible amounts of the D-Asp and D-Ser residues were observed in most of the proteins stored at $\mathrm{pH} 9.5$.

\section{Experimental}

\subsection{Materials}

Standard peptides consisting of only L- or D-amino acid residues, $\mathrm{NH}_{2}$-Gly-Pro-Glu-Ala-Asp-Ser-Gly-OH, were products of Watanabe Chemical Industries (Hiroshima, Japan). OVA and HSA were obtained from Sigma Aldrich (St. Louis, MO, USA). HEL and HL were kindly provided by $\mathrm{T}$. Ueda (expressed and purified in his laboratory, Kyushu University, Fukuoka, Japan). Racemic mixtures of Asp and Ser were purchased from Nacalai Tesque (Kyoto, Japan); those of Ala, Glu and Pro were from Wako Pure Chemical Industries (Osaka, Japan), Tokyo Chemical Industry (Tokyo, Japan) and Kanto Chemical (Tokyo, Japan), respectively. The L-enantiomers of Ala, Asp and Ser were obtained from Nacalai Tesque, while those of Glu and Pro were obtained from Wako. The D-enantiomer of Asp was from Nacalai Tesque and the others were from Wako. Deuterium chloride $\left({ }^{2} \mathrm{HCl}\right)$ and deuterium oxide $\left({ }^{2} \mathrm{H}_{2} \mathrm{O}\right)$ were purchased from Acros Organics (Geel, Belgium). NBD-F was a product of Tokyo Chemical Industry. Acetonitrile $(\mathrm{MeCN})$ and methanol $(\mathrm{MeOH})$ of HPLC grade were purchased from Nacalai Tesque and Wako, respectively. Boric acid, trifluoroacetic acid (TFA) and formic acid (FA) were from Wako. Water was purified by a Milli-Q Integral 3 system (Merck Millipore, Darmstadt, Germany). All other reagents were of the highest reagent grade and used without further purification.

\subsection{Sample preparation of proteins and ${ }^{2} \mathrm{HCl}^{2} \mathrm{H}_{2} \mathrm{O}$ hydrolysis}

OVA $(100 \mu \mathrm{g})$ was stored at $37^{\circ} \mathrm{C}$ for 1 week in $100 \mu \mathrm{L}$ of the following buffer solutions $(50 \mathrm{mM}$ sodium acetate buffer of $\mathrm{pH} 4.0,50 \mathrm{mM}$ potassium phosphate buffer of $\mathrm{pH}$ 7.4 and $100 \mathrm{mM}$ glycine/ $\mathrm{NaOH}$ buffer of $\mathrm{pH} 9.5$ ). OVA, HSA, HEL and HL were also stored at $\mathrm{pH} 9.5$ and $37^{\circ} \mathrm{C}$ for 4 weeks. These protein samples were dialyzed against water and the dialysates were collected. The peptides were dissolved in water $(1 \mu \mathrm{g} / \mu \mathrm{L})$. The protein and 
peptide samples $(30 \mu \mathrm{L})$ were dried and hydrolyzed at $110^{\circ} \mathrm{C}$ for $20 \mathrm{~h}$ with the vapor of $6 \mathrm{M}^{2} \mathrm{HCl} /{ }^{2} \mathrm{H}_{2} \mathrm{O}$. After hydrolysis, the dried residues were dissolved in $100 \mu \mathrm{L}$ of water. To $20 \mu \mathrm{L}$ of the solution, $400 \mathrm{mM} \mathrm{Na-borate} \mathrm{buffer}$ (pH 8.0) and $40 \mathrm{mM}$ NBD-F in $\mathrm{MeCN}$ were added and heated at $60^{\circ} \mathrm{C}$ for $2 \mathrm{~min}$. To stop the reaction, $65 \mu \mathrm{L}$ of an aqueous $0.5 \%$ (v/v) TFA solution was added and $20 \mu \mathrm{L}$ of the mixture was subjected to the 2D-HPLC MS/MS system described in Section 2.3.

\subsection{D-HPLC MS/MS determination of NBD-amino acid enantiomers}

As the 2D-HPLC apparatus, the Nanospace SI-2 series (Shiseido, Tokyo, Japan) was used. The first dimension of the 2D-HPLC system was composed of two pumps (3301), an auto sampler (3033), a column oven (3004) and a UV detector (3002). For the reversed-phase separation, a capillary monolithic ODS column, ML-1000 (0.53 mm i.d. x $1000 \mathrm{~mm}$, designed by the collaboration with Shiseido), was used at $40^{\circ} \mathrm{C}$. By using this column, the NBD-D- and L-amino acids were isolated and manually fractionated as mixtures of the D- and L-forms using the gradient elution of aqueous $5-18 \% \mathrm{MeCN}$ solutions containing TFA (isocratic elution with $5 \% \mathrm{MeCN}$ for 35 min and linear gradient from $5 \%$ to $18 \% \mathrm{MeCN}$ for $20 \mathrm{~min}$ and additional isocratic elution with $18 \% \mathrm{MeCN}$ for $45 \mathrm{~min}, 25 \mu \mathrm{L} / \mathrm{min}$ ). The second dimension of the system was composed of a degasser (3202), two pumps (3201), an auto sampler (3023), a high pressure valve (3011) and a column oven (3014). For the chiral separation, an enantioselective column, KSAACSP-001S (1.5 mm i.d. x $250 \mathrm{~mm}$, original column produced by the collaboration with Shiseido) was used at $25^{\circ} \mathrm{C}$. By using the column, the NBD-D- and L-amino acids were separated. The detection of the NBD-amino acid enantiomers was carried out by the absorbance at 470 $\mathrm{nm}$ and by the multiple reaction monitoring mode using a tandem mass spectrometer (Triple Quad ${ }^{\mathrm{TM}}$ 5500, Sciex,
Table 1. MS/MS conditions for the determination of NBD-Ala, Asp, Glu, Pro and Ser enantiomers.

\begin{tabular}{|c|c|c|c|c|c|c|c|c|c|c|}
\hline \multirow{2}{*}{$\begin{array}{c}\text { Amino } \\
\text { acid }\end{array}$} & \multicolumn{10}{|c|}{ MS/MS condition } \\
\hline & IS & GS1 & GS2 & CUR & $\mathrm{CAD}$ & TEM & $\mathrm{DP}$ & EP & $\mathrm{CE}$ & CXP \\
\hline Ala & 5500 & 40 & 80 & 35 & 12 & 700 & 121 & 10 & 21 & 20 \\
\hline Asp & 5500 & 50 & 50 & 20 & 8 & 650 & 126 & 10 & 35 & 12 \\
\hline Glu & 5500 & 40 & 80 & 20 & 8 & 700 & 131 & 10 & 27 & 8 \\
\hline Pro & 5500 & 50 & 80 & 20 & 8 & 700 & 95 & 10 & 21 & 18 \\
\hline Ser & 5500 & 70 & 70 & 30 & 12 & 650 & 100 & 10 & 31 & 24 \\
\hline
\end{tabular}

IS: ionspray voltage (V), GS1: ion source gas 1 (psi), GS2: ion source gas 2 (psi), CUR: curtain gas (psi), CAD: collision gas (psi), TEM: temperature $\left({ }^{\circ} \mathrm{C}\right)$, DP: declustering potential (V), EP: entrance potential $(\mathrm{V}), \mathrm{CE}$ : collision energy $(\mathrm{eV}), \mathrm{CXP}$ : collision cell exit potential (V).

Framingham, MA, USA). The precursor and product ions (positive-ion mode) of NBD-Ala, NBD-Asp, NBD-Glu, NBD-Pro and NBD-Ser were 253/236, 299/149, 313/149, 279/262 and 269/206, respectively. The MS/MS conditions are summarized in Table 1.

\section{Results and discussion}

3.1. Determination of $D$ - and L-amino acid residues using a 2D-HPLC MS/MS system

In order to quantify the D- and L-amino acid residues, the protein samples were hydrolyzed using ${ }^{2} \mathrm{HCl} /{ }^{2} \mathrm{H}_{2} \mathrm{O}$, and the produced amino acids were derivatized with NBD-F, and introduced into the 2D-HPLC MS/MS system. In the first dimension, the fractions of the target NBD-amino acids were isolated from the other amino acids by the monolithic ODS column within $90 \mathrm{~min}$ using the aqueous $\mathrm{MeCN}$ gradient elution procedure described in Section 2.3. The chromatogram obtained by the reversed-phase separation is shown in Fig. 1A in which all of the target amino acids (NBD-Ser, NBD-Asp, NBD-Glu, NBD-Ala and NBD-Pro) were baseline separated. The fractions were introduced into the second dimension, and the NBD-D- and L-amino acids were further stereoselectively separated.
(A)

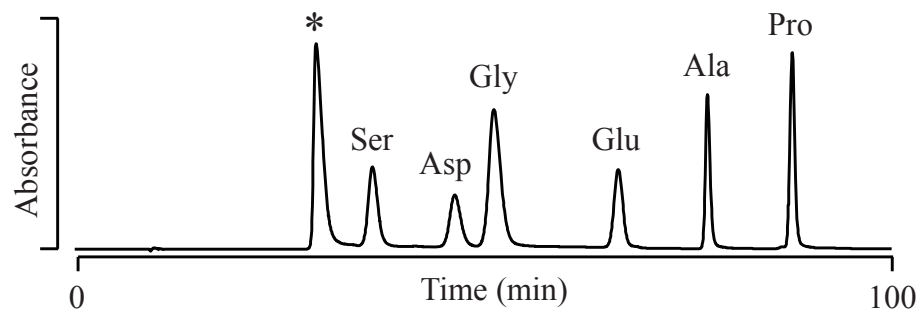

(B)

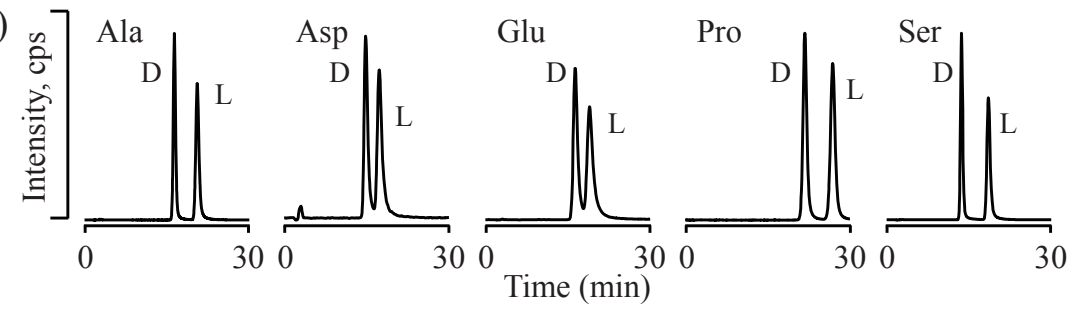

Fig. 1. Separation of the NBD-amino acids derived from the model peptide by the monolithic ODS column (A) and enantiomer separations of racemic mixtures (B) by the enantioselective column (KSAACSP-001S). The detailed separation conditions are described in the text. The reagent peak is indicated by an asterisk (*). 
An originally designed enantioselective column, KSAACSP-001S, was used for the chiral stationary phase, and the mobile phase conditions were investigated. As a result, for the separation of the NBD-Ala enantiomers, $0.1 \%$ FA in a mixture of $\mathrm{MeCN} / \mathrm{MeOH}(20 / 80, \mathrm{v} / \mathrm{v})$ was selected $(\mathrm{Rs}=3.96)$. As for the separation of the Asp and Glu enantiomers, the selected mobile phases were $0.5 \% \mathrm{FA}$ in a mixture of $\mathrm{MeCN} / \mathrm{MeOH}(80 / 20, \mathrm{v} / \mathrm{v}, \mathrm{Rs}=1.68)$ and $0.3 \%$ $\mathrm{FA}$ in a mixture of $\mathrm{MeCN} / \mathrm{MeOH}(80 / 20, \mathrm{v} / \mathrm{v}, \mathrm{Rs}=1.65)$, respectively. In case of the separation of the Pro and Ser enantiomers, $0.2 \%$ FA in a mixture of $\mathrm{MeCN} / \mathrm{MeOH}(20 / 80$, v/v) was adopted (the Rs for Pro was 3.41 and that for Ser was 4.78). The flow rate of these mobile phases were 150 $\mu \mathrm{L} / \mathrm{min}$. As shown in Fig. 1B, all of the target NBD-amino acid enantiomers were separated within $30 \mathrm{~min}$, and in all cases, the D-forms eluted faster than the L-forms. The determination of the target amino acids was carried out by a triple quadrupole mass spectrometer using the precursor/product ion pairs described in Section 2.3., and the amino acids racemized/deuterized during hydrolysis were discriminated by the increase in their molecular weights.

In order to validate the present 2D-HPLC MS/MS system, the linearity of the calibration lines and the precision of the determination were tested by a model peptide $\left(\mathrm{NH}_{2}\right.$-Gly-Pro-Glu-Ala-Asp-Ser-Gly-OH). Since the presence of some strain in the calculation of conformational energy for a trans-L-Pro residue [33], we designed the peptide based on the fact that Gly-Pro sequence in a protein has less conformational energy [34]. The calibration lines for all of the target $\mathrm{D}$-amino acid residues $(\% \mathrm{D})$ were linear with correlation coefficients higher than 0.998 . The RSD values of the intra-day precision and the inter-day precision determined by the model peptide were lower than $5.0 \%$ $(n=3)$. These results are summarized in Table 2 .

Table 2. Calibration lines, intra-day precision and inter-day precision for the determination of 5 amino acid residues in the model peptide.

\begin{tabular}{|c|c|c|c|c|}
\hline \multirow{2}{*}{$\begin{array}{c}\text { Amino } \\
\text { acid }\end{array}$} & \multicolumn{2}{|c|}{ Calibration line } & \multicolumn{2}{|c|}{ Precision (RSD\%) } \\
\hline & Equation & $\begin{array}{l}\text { Correlation } \\
\text { coefficient }\end{array}$ & Intra-day & Inter-day \\
\hline Ala & $y=0.95 x+0.00$ & 0.9997 & 1.58 & 2.60 \\
\hline Asp & $y=1.24 x+0.00$ & 0.9985 & 4.48 & 4.13 \\
\hline Glu & $y=0.98 x+0.00$ & 0.9987 & 2.52 & 3.03 \\
\hline Pro & $y=1.04 x+0.00$ & 0.9994 & 1.30 & 0.85 \\
\hline Ser & $y=1.27 x+0.00$ & 0.9996 & 2.14 & 2.58 \\
\hline
\end{tabular}

Several reports have already been published about the investigation of D-amino acid residues in proteins. The amino acid residues existing at the $N$-terminal of the peptides/proteins were obtained as their phenylthiocarbamoyl amino acids (PTC-AAs) by Edman degradation and sequentially and enantioselectively determined using the combination of a reversed-phase column and a tandemly connected enantioselective column [25]. Although the Edman degradation is useful for determination of $\mathrm{N}$-terminal amino acids, it is practically inappropriate for determination of all the amino acid residues in a whole protein because there are many amino acid residues in the proteins and the yield of the cleavage reaction is limited. The D-amino acid residues in proteins can also be determined by peptide analysis following the digestion with proteases. These peptides were analyzed as the diastereomers by reversed-phase HPLC [26] or LC-MS/MS [27]. The analysis of the diastereomeric peptides is effective, however, it is mainly intended for the peptides containing the Asp isomers and also requires the synthetic peptides consistent with the digestive products. Since several D-amino acid residues, such as D-Ser and D-Asn, were detected in addition to the Asp isomers [18,35] the screening of amino acid residues in a comprehensive manner is expected.

Considering these situations, acid hydrolysis in combination with the chiral amino acid analysis is one of the practical solutions. Normally, amino acid residues in the proteins are frequently racemized during hydrolysis [28]. By using ${ }^{2} \mathrm{HCl} /{ }^{2} \mathrm{H}_{2} \mathrm{O}$ instead of $\mathrm{HCl} / \mathrm{H}_{2} \mathrm{O}$, the $\alpha$-hydrogen of the D-amino acid racemized during hydrolysis was replaced by deuterium. Therefore, the method using ${ }^{2} \mathrm{HCl} /{ }^{2} \mathrm{H}_{2} \mathrm{O}$ is effective to distinguish the amino acid residues originally present in the proteins and those racemized/epimerized during hydrolysis. Until now, the analysis using ${ }^{2} \mathrm{HCl} /{ }^{2} \mathrm{H}_{2} \mathrm{O}$ hydrolysis followed by GC-MS was reported by Liardon et al. in 1981 [29]. In 2010, Miyamoto et al. adopted the hydrolysis with the vapor of ${ }^{2} \mathrm{HCl} /{ }^{2} \mathrm{H}_{2} \mathrm{O}$ and the obtained amino acids were analyzed by LC-MS/MS [30]. These methods were useful for the sensitive screening of D-amino acid residues in proteins/peptides, however, there is still some room for optimization of the separation/detection conditions, and also to have broadened the analytical target amino acid residues.

We have already reported a 2D-HPLC MS/MS method combining ${ }^{2} \mathrm{HCl} /{ }^{2} \mathrm{H}_{2} \mathrm{O}$ hydrolysis, NBD-derivatization and 2D-LC separation to determine trace amounts of D-amino acid residues in the proteins [31]. For the procedure, two enantioselective columns (Sumichiral OA-3200S and KSAACSP-001S, $1.5 \mathrm{~mm}$ i.d. x $250 \mathrm{~mm}$ ) were adopted to determine five major amino acids in the second dimension, and development of a simpler method is expected. In addition, the detection limits for the D-Asp and D-Glu residues were not sufficient and selection of the precursor/ product ion pairs and optimization of the detection conditions were further required for the NBD-Asp and Glu. In the present study, only one enantioselective column (KSAACSP-001S, $1.5 \mathrm{~mm}$ i.d. x $250 \mathrm{~mm}$ ) is used for the second dimension, and newly discovered precursor/product 

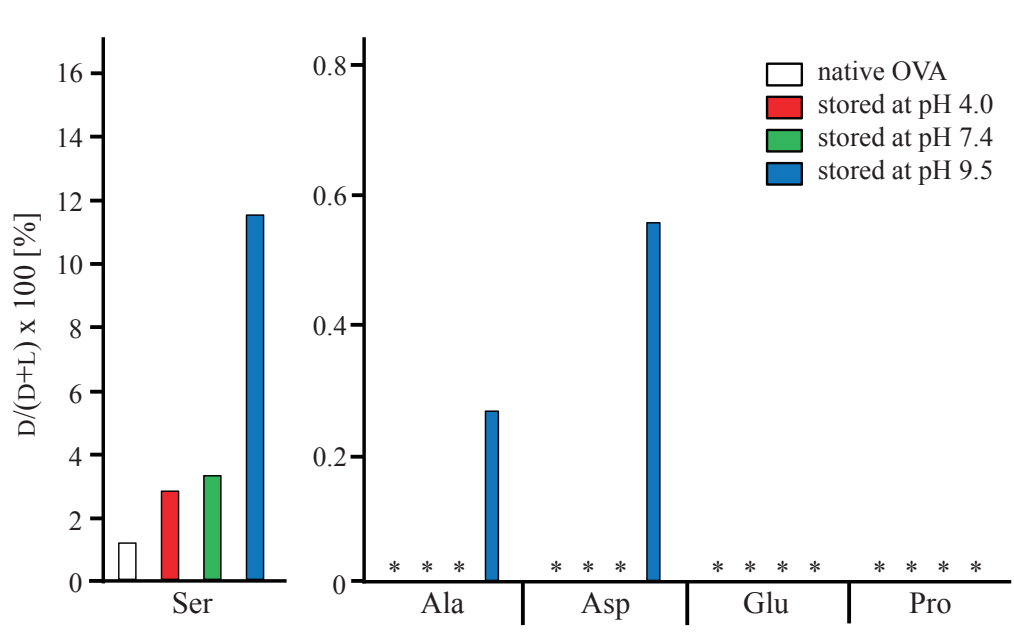

Fig. 2. Proportions of D-amino acid residues in OVA stored under different $\mathrm{pH}$ conditions for a week at $37^{\circ} \mathrm{C}$. * less than lower limit of quantification.

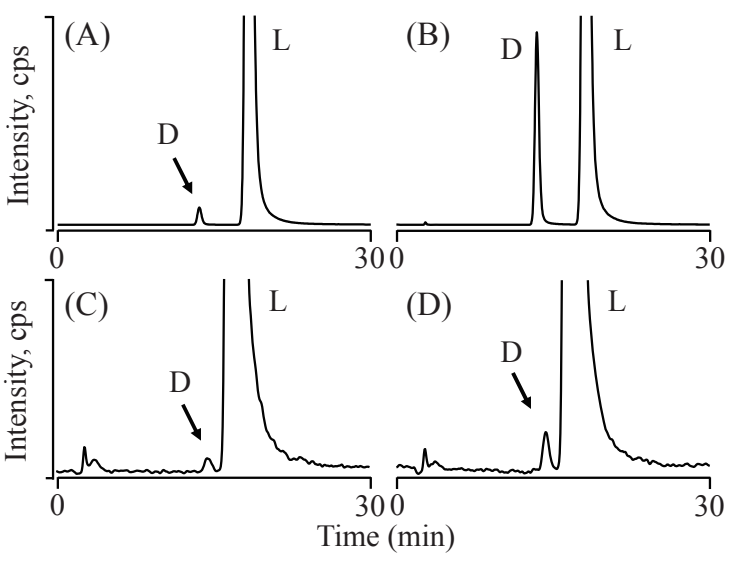

Fig. 3. Analysis of Ser enantiomers in native OVA (A) and that in OVA stored for a week at $\mathrm{pH} 9.5$ and at $37^{\circ} \mathrm{C}$ (B). The results for the Asp enantiomers in the native OVA (C) and that in the OVA stored for a week at $\mathrm{pH}$ 9.5 and at $37^{\circ} \mathrm{C}(\mathrm{D})$. ion pairs (299/149 and 313/149) were used for NBD-Asp and Glu to improve the detection limits $(0.2 \% \mathrm{D}$ isomers $)$. The present method was validated and applications to various proteins are expected.

\subsection{Formation of D-amino acid residues in ovalbumin stored under various $\mathrm{pH}$ conditions}

To estimate the effect of the $\mathrm{pH}$ conditions on the formation of the D-amino acid residues in the proteins, OVA was selected as a model protein and was stored at $\mathrm{pH} 4.0$, 7.4 and 9.5 for a week at $37^{\circ} \mathrm{C}$. The amino acid residues were enantioselectively analyzed using the 2D-HPLC MS/MS procedure described in Section 3.1. As the control, native OVA was also analyzed (OVA was dissolved in water and hydrolyzed immediately with ${ }^{2} \mathrm{HCl} /{ }^{2} \mathrm{H}_{2} \mathrm{O}$, and the obtained free NBD-amino acids were analyzed by the 2D-HPLC MS/MS). The values of $\% \mathrm{D}(\mathrm{D} /(\mathrm{D}+\mathrm{L}) \times 100)$ observed in the native OVA were $1.1 \%$ for Ser and lower than $0.2 \%$ for the other amino acids. These results showed that even in the native proteins, non-negligible amounts of the D-amino acid residues (in this case, D-Ser) were observed. In the present study, moderate acidic and alkaline conditions were selected to accelerate the denaturation of the proteins. In case of OVA stored at $\mathrm{pH}$ 4.0 , only the $\% \mathrm{D}$ value of Ser increased to $2.8 \%$, while those of the other amino acid residues remained almost constant. In case of OVA stored at $\mathrm{pH} 7.4$, only the $\% \mathrm{D}$ value of Ser increased to $3.3 \%$, and those of the other amino acid residues were negligible. On the other hand, when stored at $\mathrm{pH} 9.5$, the values of $\% \mathrm{D}$ were $11.5 \%$ for Ser, $0.6 \%$ for Asp and $0.3 \%$ for Ala (the values for Glu and Pro were less than $0.2 \%$ ). A remarkably high $\% \mathrm{D}$ value of Ser was observed, and those of Asp and Ala also increased. The \%D values of the Glu and Pro residues remained low. All of these $\%$ D values are summarized in Fig. 2. Figure 3 shows the chromatograms obtained for the Ser and Asp residues in the native OVA and that stored at $\mathrm{pH}$ 9.5. As mentioned in Section 3.1., NBD-D-Ser and NBD-D-Asp eluted faster than NBD-L-Ser and NBD-L-Asp. In OVA stored at $\mathrm{pH}$ 9.5, the peaks of D-Ser and D-Asp were larger than those determined in the native OVA. On the other hand, no drastic difference was observed in the chromatograms obtained for the OVA stored at $\mathrm{pH} 4.0$ and 7.4 .

OVA, a major protein component of chicken egg white, is reported to change into S-OVA which is a heat-stable form produced as the $\mathrm{pH}$ inside the egg increases during storage [36,37]. Based on the crystal structure analysis, Yamasaki et al. clarified that S-OVA contained Ser164, Ser236 and Ser320 as the irreversibly converted D-forms and these D-Ser residues might contribute to the thermostabilization of S-OVA [38]. In fact, the denaturation temperature of S-OVA was higher than that of the native OVA. Ishimaru et al. investigated the role of these D-Ser residues in S-OVA using three mutant OVAs (S164A, S236A and S320A) treated under alkaline conditions [39]. In their report, it was clarified that D-Ser164 and D-Ser320 caused by alkaline exposure have several interactions with other amino acid residues in OVA, and play crucial roles in the stabilization of S-OVA.

In the present study, a remarkably high \%D value of Ser was obtained from OVA stored at $\mathrm{pH} 9.5$ for a week, and is quite consistent with the previous reports [32]. It is also consistent with our former report [31] that a non-negligible amount of the D-Ser residues existed in the native OVA purchased and stored in a refrigerator. On the other hand, the amounts of the D-Ala, D-Asp, D-Glu and D-Pro residues in OVA were investigated for the first time after storage under different $\mathrm{pH}$ conditions. Not only D-Ser, but also the D-Asp residues were accumulated and a trace level of 
D-Ala residues existed in the OVA stored at $\mathrm{pH} 9.5$ and not at $\mathrm{pH} 4.0$ and 7.4. The physiological meanings of these D-Asp and D-Ala residues are still unclear, and further studies are ongoing.

\subsection{Formation of D-amino acid residues in various proteins stored under alkaline conditions}

To examine the difference in the D-amino acid formation in various proteins, the D-Ala, D-Asp, D-Glu, D-Pro and D-Ser residues were analyzed in 4 different proteins. As the target proteins, HSA, HEL and HL were selected in addition to OVA. Since the increase of the D-amino acid residues in proteins was likely to occur under alkaline conditions, these proteins were stored at $\mathrm{pH} 9.5$ for 4 weeks. The protein samples were prepared as described in Section 2.2., and subjected to the 2D-HPLC MS/MS system. In OVA, the $\% \mathrm{D}$ value of Ser prominently increased to $14.0 \%$, and the $\% \mathrm{D}$ value of Asp was four times higher than that in the native OVA. Compared with the results stored for a week, similar or higher values of the D-amino acid residues were observed after the storage for 4 weeks. In HSA, the $\% \mathrm{D}$ values of Ser and Asp increased to $0.6 \%$ and $0.5 \%$, respectively, after storage for 4 weeks. On the other hand, the values were less than $0.2 \%$ and $0.3 \%$ in the native HSA. The value of D-Ala obtained in HSA reached $0.2 \%$. In the case of HEL and HL, relatively high amounts of the D-Ser and D-Asp residues were observed although the amounts of these residues were low in the native proteins. The \%D values of Ser increased to $1.3 \%$ and $1.1 \%$ in HEL and $\mathrm{HL}$, respectively, and the \%D values of Asp increased to $1.5 \%$. On the other hand, the \%D values of Glu and Pro remained low even after storage for 4 weeks (Table 3 ).

Table 3. Values of $\% \mathrm{D}$ for 5 amino acids observed in the proteins.

\begin{tabular}{ccccccc}
\hline \multirow{2}{*}{ Protein } & $\begin{array}{c}\text { Storage } \\
(\text { Day })\end{array}$ & \multicolumn{5}{c}{ Amino acid (\%D) } \\
\cline { 3 - 7 } & 0 & Ala & Asp & Glu & Pro & Ser \\
\hline \multirow{2}{*}{ OVA } & 28 & 0.2 & 0.8 & - & - & 14.0 \\
& 0 & - & 0.3 & - & - & - \\
\multirow{2}{*}{ HSA } & 28 & 0.2 & 0.5 & - & - & 0.6 \\
\hline \multirow{2}{*}{ HEL } & 0 & - & 0.3 & - & - & - \\
& 28 & - & 1.5 & - & 0.2 & 1.3 \\
\hline \multirow{2}{*}{ HL } & 0 & - & 0.4 & - & - & - \\
& 28 & - & 1.5 & - & 0.2 & 1.1 \\
\hline
\end{tabular}

-: lower than $0.2 \%$.

Until now, the presence of D-Asp residues was clarified in various tissues and proteins from aged donors. In the tooth enamel and dentine proteins, the amounts of the D-Asp residues increased by aging [40,41]. Using 19-20 human samples, Helfman and Bada showed that the values of $\% \mathrm{D}-\mathrm{Asp}$ in the enamel and dentine proteins have a clear correlation with the age of the donors (from 8-78 years old).
In the sun-exposed skin, Fujii et al. demonstrated that ultraviolet irradiation caused the formation of D-Asp in the elastic fibers by using the antibodies against the D-Asp-containing peptide [42]. As for elastin from the human aorta, Powell et al. reported that the \%D-Asp in the tissue increased linearly with age from $3.9 \%$ at the age of 18 to $12.9 \%$ at the age of 85 [17]. In the human brain, $\mathrm{D}$-Asp residues were observed in the myelin basic proteins. Fisher et al. demonstrated that the D-Asp residues in the myelin basic proteins were higher than that in the white matter [43]. The presence of isomerized Asp residues was also shown in $\alpha \mathrm{A}$-crystallin from human lens and the isomerization is thought to have an influence on the stability of the crystallins $[16,44]$. In the $\beta$-amyloid proteins, Shimizu et al. reported that isomerization of Asp23 was accumulated in the plaques and vascular, and the isomerization raised the aggregation of the proteins [45] The presence of $\mathrm{D}$-Ser residues were also clarified in the $\beta$-amyloid proteins [18]. From the patients with Alzheimer's disease, Shapira et al. reported that relatively large proportions of D-Ser as well as D-Asp were observed in the $\beta$-amyloid proteins. Although most of these reports focused on the D-Asp and D-Ser residues, other D-amino acid residues, such as D-Phe [46] and D-Asn [35], have also been reported, and the determination of multiple D-amino acid residues is highly expected for the screening of novel biomarkers of diagnoses.

In the present study, not only the D-Asp and D-Ser residues, but non-negligible amounts of the D-Ala residues were found in OVA and HSA using the 2D-HPLC MS/MS system following the ${ }^{2} \mathrm{HCl} /{ }^{2} \mathrm{H}_{2} \mathrm{O}$ hydrolysis. Significant amounts of the D-Ser and D-Asp residues were also observed in all 4 tested proteins. Because the relationships between the isomerization of the amino acid residues and age-related diseases have been frequently reported, the accumulation of D-amino acid residues might also have some physiological meanings in the albumin and lysozyme. The present 2D-HPLC MS/MS analysis together with ${ }^{2} \mathrm{HCl} /{ }^{2} \mathrm{H}_{2} \mathrm{O}$ hydrolysis is, in principle, able to expand to the determination of all proteinogenic amino acid residues, and further studies to reveal the implications of the D-amino acid residues and functional changes of the proteins are ongoing.

\section{Conclusion}

In the present investigation, a 2D-HPLC MS/MS procedure has been developed in combination with ${ }^{2} \mathrm{HCl} /{ }^{2} \mathrm{H}_{2} \mathrm{O}$ hydrolysis and NBD-derivatization for the determination of trace amounts of D-amino acid residues in the proteins. The D-enantiomers of the Ala, Asp, Glu, Pro and Ser residues have been analyzed in 4 proteins (OVA, HSA, HEL and HL) after storage under various $\mathrm{pH}$ conditions, and significant amounts of the D-Ser and D-Asp 
residues were found. These D-amino acid residues might have some physiological meanings in the respective proteins, and further studies are in progress.

\section{Acknowledgements}

This study was partly supported by JSPS KAKENHI Grant Number 16H05080 Japan. The authors thank Shiseido Co., Ltd., (Tokyo, Japan) for their technical support.

\section{References}

[1] Corrigan, J. J. Science 1969, 164, 142-149.

[2] Myoshi, Y.; Koga, R.; Oyama, T.; Han, H.; Ueno, K.; Masuyama, K.; Itoh, Y.; Hamase, K. J. Pharm. Biomed. Anal. 2012, 69, 42-49.

[3] Miyoshi, Y.; Oyama, T.; Itoh, Y.; Hamase, K. Chromatography 2014, 35, 49-57.

[4] Snyder, S. H.; Kim, P. M. Neurochem. Res. 2000, 25, 553-560.

[5] Hashimoto, A.; Nishikawa, T.; Oka, T.; Takahashi, K. J. Neurochem. 1993, 60, 783-786.

[6] Katane, M.; Homma, H. J. Chromatogr. B 2011, 879, 3108-3121.

[7] Takigawa, Y.; Homma, H.; Lee J.-A.; Fukushima, T.; Santa, T.; Iwatsubo, T.; Imai, K. Biochem. Biophys. Res. Commun. 1998, 248, 641-647.

[8] Nagata, Y.; Homma, H.; Lee, J.-A.; Imai, K. FEBS Lett. 1999, 444, 160-164.

[9] Nishikawa, T. J. Chromatogr. B 2011, 879, 3169-3183.

[10] Hamase, K.; Morikawa, A.; Zaitsu, K. J. Chromatogr. B 2002, 781, 73-91.

[11] Kimura, T.; Hamase, K.; Miyoshi, Y.; Yamamoto, R.; Yasuda, K.; Mita, M.; Rakugi, H.; Hayashi, T.; Isaka, Y. Sci. Rep. 2016, 6, 26137.

[12] Fukushima, T.; Santa, T.; Homma, H.; Nagatomo, R.; Imai, K. Biol. Pharm. Bull. 1995, 18, 1130-1132.

[13] Brückner, H.; Hausch, M. J. Chromatogr. 1993, 614, 7-17.

[14] Sasabe, J.; Miyoshi, Y.; Suzuki, M.; Mita, M.; Konno, R.; Matsuoka, M.; Hamase, K.; Aiso, S. Proc. Natl. Acad. Sci. USA 2012, 109, 627-632.

[15] Fujii, N.; Kaji, Y.; Fujii, N. J. Chromatogr. B 2011, 879, 3141-3147.

[16] Fujii, N.; Takata, T.; Fujii, N.; Aki, K. Biochim. Biophys. Acta 2016, 1860, 183-191.

[17] Powell, J. T.; Vine, N.; Crossman, M. Atherosclerosis 1992, 97, 201-208.

[18] Shapira, R.; Austin, G. E.; Mirra, S. S. J. Neurochem. 1988, 50, 69-74.

[19] Morikawa, A.; Hamase, K.; Zaitsu, K. Anal. Biochem. 2003, 312, 66-72.

[20] Hamase, K.; Takagi, S.; Morikawa, A.; Konno, R.;
Niwa, A.; Zaitsu, K. Anal. Bioanal. Chem. 2006, 386, 705-711.

[21] Hamase, K.; Morikawa, A.; Ohgusu, T.; Lindner, W.; Zaitsu, K. J. Chromatogr. A 2007, 1143, 105-111.

[22] Koga, R.; Miyoshi, Y.; Sato, Y.; Mita, M.; Konno, R.; Lindner, W.; Hamase, K. Chromatography 2016, 37, $15-22$.

[23] Hamase, K.; Miyoshi, Y.; Ueno, K.; Han, H.; Hirano, J.; Morikawa, A.; Mita, M.; Kaneko, T.; Lindner, W.; Zaitsu, K. J. Chromatogr. A 2010, 1217, 1056-1062.

[24] Ariyoshi, M.; Katane, M.; Hamase, K.; Miyoshi, Y.; Nakane, M.; Hoshino, A.; Okawa, Y.; Mita, Y.; Kaimoto, S.; Uchihashi, M.; Fukai, K.; Ono, K.; Tateishi, S.; Hato, D.; Yamanaka, R.; Honda, S.; Fushimura, Y.; Iwai-Kanai, E.; Ishihara, N.; Mita, M.; Homma, H.; Matoba, S. Sci. Rep. 2017, 7, 43911.

[25] Iida, T.; Matsunaga, H.; Fukushima, T.; Santa, T.; Homma, H.; Imai, K. Anal. Chem. 1997, 69, 4463-4468.

[26] Sadakane, Y.; Yamazaki, T.; Nakagomi, K.; Akizawa, T.; Fujii, N.; Tanimura, T.; Kaneda, M.; Hatanaka, Y. J. Pharm. Biomed. Anal. 2003, 30, 1825-1833.

[27] Fujii, N.; Sakaue, H.; Sasaki, H.; Fujii, N. J. Biol. Chem. 2012, 287, 39992-40002.

[28] Miyamoto, T.; Sekine, M.; Ogawa, T.; Hidaka, M.; Watanabe, H.; Homma, H.; Masaki, H. Amino Acids 2016, 48, 2683-2692.

[29] Liardon, R.; Ledermann, S.; Ott, U. J. Chromatogr. 1981, 203, 385-395.

[30] Miyamoto, T.; Sekine, M.; Ogawa, T.; Hidaka, M.; Homma, H.; Masaki, H. Chem. Biodivers. 2010, 7, 1644-1650.

[31] Ishigo, S.; Negishi, E.; Miyoshi, Y.; Onigahara, H.; Mita, M.; Miyamoto, T.; Masaki, H.; Homma, H.; Ueda, T.; Hamase, K. Chromatography 2015, 36, 45-50.

[32] Miyamoto, T.; Takahashi, N.; Sekine, M.; Ogawa, T.; Hidaka, M.; Homma, H.; Masaki, H. J. Pharm. Biomed. Anal. 2015, 116, 145-149.

[33] Schimmel, P. R.; Flory, P. J. J. Mol. Biol. 1968, 34, 105-120.

[34] Ueda, T.; Tamura, T.; Maeda, Y.; Hashimoto, Y.; Miki, T.; Yamada, H.; Imoto, T. Protein Eng. Des. Sel. 1993, 6, 183-187.

[35] Ueno, K.; Ueda, T.; Sakai, K.; Abe, Y.; Hamasaki, N.; Okamoto, M.; Imoto, T. Cell. Mol. Life Sci. 2005, 62, 199-205.

[36] Smith, M. B.; Back, J. F. Nature 1962, 193, 878-879.

[37] Smith, M. B.; Back, J. F. Aust. J. Biol. Sci. 1965, 18, 365-377.

[38] Yamasaki, M.; Takahashi, N.; Hirose, M. J. Biol. Chem. 2003, 278, 35524-35530.

[39] Ishimaru, T.; Ito, K.; Tanaka, M.; Matsudomi, N. 
Protein Sci. 2010, 19, 1205-1212.

[40] Helfman, P. M.; Bada, J. L. Proc. Natl. Acad. Sci. USA 1975, 72, 2891-2894.

[41] Helfman, P. M.; Bada, J. L. Nature 1976, 262, 279-281.

[42] Fujii, N.; Tajima, S.; Tanaka, N.; Fujimoto, N.; Takata, T.; Shimo-Oka, T. Biochem. Biophys. Res. Commun. 2002, 294, 1047-1051.

[43] Fisher, G. H.; Garcia, N. M.; Payan, I. L.; Cadilla-Perezrios, R.; Sheremata, W. A.; Man, E. H. Biochem. Biophys. Res. Commun. 1986, 135, 683-687.

[44] Fujii, N.; Satoh, K.; Harada, K.; Ishibashi, Y. J. Biochem. 1994, 116, 663-669.

[45] Shimizu, T.; Fukuda, H.; Maruyama, S.; Izumiyama, N.; Shirasawa, T. J. Neurosci. Res. 2002, 70, 451-461.

[46] Kajita, R.; Goto, T.; Lee, S. H.; Oe, T. Chem. Res. Toxicol. 2013, 26, 1926-1936. 